\title{
Obstructive Sleep Apnea Syndrome (OSAS) Decrease Concentration Levels in Young Adults
}

\author{
Fidela Hanan Zivana $^{1}$, Neni Susilaningsih ${ }^{2}$, Dwi Marilyawati ${ }^{3}$, Kanti Yunika ${ }^{3 *}$ \\ ${ }^{1}$ Faculty of Medicine, Diponegoro University \\ ${ }^{2}$ Department of Anatomy Histology, Faculty of Medicine Diponegoro Univerisity \\ ${ }^{3}$ Department of Ear, Nose Throat, Head and Neck, Faculty of Medicine Diponegoro University
}

Keywords:

Bacterial Obstructive Sleep Apnea Syndrome (OSAS)

Concentration Level,

Cognitive Function

\begin{abstract}
*) Correspondence to:
\end{abstract}
kantiyunika@gmail.com

Article history:

Received 28-11-2020

Accepted $04-12-2020$

Availableonline10-12-2020

\begin{abstract}
Background: Obstructive Sleep Apnea Syndrome (OSAS) is sleeping-disorder that's characterized by recurrent episodes of upper airway obstruction during sleep. Fourteen percent of world populations suffer from OSAS. OSA patients are 7,5 to 20 times more likely to have difficulties with concentration, learning new tasks, and execution of monotonous tasks.

Objective: The primary objective of this study was to investigate the relationship between Obstructive Sleep Apnea Syndrome (OSAS) and concentration level in young adults

Methods: This is an analytic observational study with cross-sectional design. Sampling was carried out with total sampling. Samples that qualified the inclusion and exclusion criteria were assessed by OSAS using the Epworth Sleepiness Scale (ESS) questionnaire and Digit Symbol Substitution Test was used to assess the concentration level. The data were analyzed, using the chi-square test and the prevalence (PR) test

Results: The Chi-square test showed that there was a significant relationship between OSAS and concentration level $(\mathrm{p}=0.033)$. The Prevalence Ratio test found that OSAS decreased concentration level by 1,55 compared to not OSAS

Conclusion: There was a significant relationship between OSAS and concentration level in young adults. OSAS patients are 1,55 more likely to have a decrease concentration level when compared with healthy individuals
\end{abstract}

DIMJ, 2020, 1(2), 46-49 DOI: https:/ / doi.org/10.14710/dimj.v1i2.9543

\section{Introduction}

Obstructive Sleep Apnea Syndrome (OSAS) is a characterized by recurrent episodes of upper airway obstruction for 10 seconds or more during sleep. ${ }^{1}$ Fourteen percent of world population who suffer from sleep disorders experience OSAS. ${ }^{2}$ The prevalence of OSAS among the general population is high and it is estimated that $11.4 \%$ for men and $4,7 \%$ for women, and its prevalence is even greater with up to $22 \%$ every year. The highest prevalence of OSAS incidence in young adults is $15-24 \%$. $^{3,4}$

Cases of OSAS that are not diagnosed early can cause various conditions, including hypertension, coronary heart disease, diabetes mellitus, heart failure, stroke, cognitive impairment, depression, decreased learning ability, and decrease quality of life. Thus makes OSAS a major public health problem, with high rates of morbidity, mortality, health costs, and safety risks. ${ }^{5,6} 11-71 \%$ of OSAS patients also have cognitive impairement. ${ }^{7,8}$

The relationship between OSAS with inattention and concentration problems are associated with Excessive Daytime Sleepiness (EDS) caused by the intermittent hypoxia mechanism. ${ }^{8-11}$ Hypoxia can increase the formation of Reactive Oxygen Species (ROS) which has the potential to damage brain cells that may be the major factor implicated in OSAS-related cognitive dysfunction. ${ }^{12,13}$

For adults, including students, concentration is needed in the process of academic performance and quality of life. 
In previous studies, medical students were assessed as having poor sleep quality and quantity. Concentration is one of the important things that every doctor must have, which affects the level of professionalism and empathy of a doctor. ${ }^{14,15}$ The aim of this study was to investigate the relationship and strong relationship between Obstructive Sleep Apnea Syndrome (OSAS) and concentration level in young adults.

\section{Methods}

This research is an observational-analytic study with a cross sectional design using primary data from the Epworth Sleepiness Scale (ESS) test result, and Digit Symbol Substitution Test (DSST) result. Samples were young adults, specifically medical students of Diponegoro University class of 2019 which were obtained by online from July-August 2020.

In this study, a total sampling technique was used where result data that met the inclusion and exclusion criteria were used as the study sample. The inclusion criteria in this study were all medical students class of 2019, faculty of medicine, Diponegoro University, which includes age 18-23 years old with normal Body Mass Index who were consented. The exclusion criteria in this study were subjects who had a history of head trauma and experienced depression, anxiety, and stress as measured by Depression Anxiety Stress Scales (DASS-21). OSAS was measured by Epworth Sleepiness Scales (ESS). A score of 10-24 is categorized as OSAS, whereas a score less than 10 is categorized as non-OSAS. The concentration level was measured by the Digit Symbol Substitution test (DSST). DSST scores higher than 63 represents a better concentration than those who scored less than 63. The ESS and DASS-21 questionnaires were filled via Google Form. Subsequently, an online DSST test was conducted simultaneously for 90 seconds.

The data were analyzed by the computer statistical analysis program, where nominal data, includes OSAS, concentration level, and gender were analyzed by the chi-square test. The association between OSAS and concentration levels was determined by Prevalence Ratio (PR). Ethical Clearance was obtained from the Health Research Ethics Commission, Faculty of Medicine, Diponegoro University, Semarang. Number 122/EC/KEPK/FK-UNDIP/VI/2020.

\section{Results}

This study was conducted from July- August 2020. A total of 229 samples were obtained from which 92 met the inclusion and exclusion criteria. Twenty four $(26.1 \%)$ of the subjects experienced OSAS from which $9(37.5 \%)$ were men and 15 $(62.15 \%)$ were women. Those who did not experience OSAS includes $68(73.9 \%)$ subjects from which $31(45.59 \%)$ were men and $37(54.41 \%)$ women. Forty eight subjects with poor concentration were found in this study, where 22 (45.83\%) of them were men and $26(54.17 \%)$ were women. While 44 others were found with good concentration from which $18(40.90 \%)$ were men and $26(59.09 \%)$ were women. Gender was a confounding variable that had a p-value of 0.492 on OSAS and 0.634 on concentration levels which implies that they don't affect one another.

The result of the bivariate test between OSAS and concentration levels can be seen in table1.

Table 1. Chi-square test results

\begin{tabular}{llll}
\hline & \multicolumn{2}{c}{ Concentration levels } & \multirow{2}{P}{} \\
\cline { 2 - 3 } & $\begin{array}{l}\text { Less } \\
\text { concentration }\end{array}$ & $\begin{array}{l}\text { Good } \\
\text { concentration }\end{array}$ & value \\
\hline OSAS & 17 & 7 & 0.033 \\
Not & 31 & 37 & \\
OSAS & & & \\
\hline
\end{tabular}

Results show that there is a significant relationship between OSAS and concentration level. $(\mathrm{p}=0.033)$.

Table 2. The OSAS Prevalence Rate with concentration levels

\begin{tabular}{lllll}
\hline & \multicolumn{2}{c}{ Concentration levels } & total \\
\cline { 3 - 4 } & & $\begin{array}{l}\text { Less } \\
\text { concentration }\end{array}$ & $\begin{array}{l}\text { Good } \\
\text { concentration }\end{array}$ \\
\hline & OSAS & 17 & 7 & 24 \\
& Not & 31 & 37 & 68 \\
& OSAS & & & \\
Total & & 48 & 44 & 92 \\
\hline
\end{tabular}

Prevalence Ratio of the study was 1.55 . It shows that OSAS has a 1.55 times higher risk of lowering concentration.

\section{Discussion}

Based on this study, women were more likely to experience OSAS than men $(62.5 \%$ vs $37.5 \%)$ which contradicts the existing theory where the incidence of OSAS is twice higher in men than women due to hormonal effects, differences in body fat distribution, and differences in pharyngeal anatomy and function. ${ }^{16-18}$ This finding can be caused by the subject distribution itself, where in this study women dominates more than half of the population. The results of this study were not 
affected by the BMI for all BMI ranges were normal.

A subject who has poor concentration were more likely to be women $(54.17 \%)$ than men $(45.83 \%)$. This is associated with a larger brain volume and more dominant hemispheric connectivity in men. ${ }^{19,20}$

It was found that OSAS was significantly related to the concentration level $(\mathrm{p}=0.033)$. This is similar to previous studies which shows a positive correlation between OSAS and cognitive impairments. It was stated that patients with OSAS had a greater cognitive impairment, attention disorder, psychomotor speed disorder, and impaired executive function than patients without OSAS. ${ }^{21}$

Prevalence Ratio obtained from this study was 1.55. It implies that OSAS increases the decrease of concentration 1.55 times. This is consistent with previous studies where OSAS is associated with a 1.5 times greater risk of cognitive impairment than normal population. Furthermore, the theory explained that OSAS is a contributing risk factor for cognitive impairment such as inattention, less concentration, delayed memory, and decreased learning skills. ${ }^{22,23}$

\section{Conclusion}

There was a positive/significant relationship between OSAS and concentration level in young adults. OSAS patients were 1.55 more likely to have a decreased concentration than healthy individuals.

\section{Author Contribution}

All authors have contributed to all process in this research, including preparation, analysis, and approval for publication of this manuscript.

\section{Funding}

The authors are responsible for all of this research funding without the involvement of grant or any external source.

\section{Conflict of Interest}

The authors declare no conflict of interest regarding the publication of this article.

\section{References}

1. He L, Wang B, Lang WY, Xue J, Zhao DL, Li GF, et al. Genetically-reduced serum ACE activity might be a causal risk factor for obstructive sleep apnea syndrome: A metaanalysis. Sci Rep. 2015;5(May):1-9.

2. Gupta R, Das S, Gujar K, Mishra KK, Gaur N, Majid A. Clinical Practice Guidelines for Sleep Disorders [Internet]. Vol. 59, Indian journal of psychiatry. Medknow Publications \& Media Pvt
Ltd; 2017 [cited 2017 Jan 3]. p. S116-38. Available from:

https://pubmed.ncbi.nlm.nih.gov/28216789

3. Ahmad M, Makati D, Akbar S. Review of and Updates on Hypertension in Obstructive Sleep Apnea. Int J Hypertens. 2017;2017.

4. Fassbender P, Bürgener S, Haddad A, Silvanus MT, Peters J. Perioperative incidence of airway obstructive and hypoxemic events in patients with confirmed or suspected sleep apnea - a prospective, randomized pilot study comparing propofol/remifentanil and sevoflurane/remifentanil anesthesia. BMC Anesthesiol. 2018;18(1):1-7.

5. Kaffah S, Susanto AD. Pengaruh Obstructive Sleep Apnea ( OSA ) Terhadap Fungsi Kognitif. J Respirologi Indones. 2015;35(4):247-59.

6. Osman AM, Carter SG, Carberry JC, Eckert DJ. Obstructive sleep apnea: current perspectives. Nat Sci Sleep. 2018;10:21-34.

7. Krysta K, Bratek A, Zawada K, Stepańczak R. Cognitive deficits in adults with obstructive sleep apnea compared to children and adolescents. J Neural Transm. 2017;124:187201.

8. Mubashir T, Abrahamyan L, Niazi A, Piyasena $\mathrm{D}$, Arif AA, Wong $\mathrm{J}$, et al. The prevalence of obstructive sleep apnea in mild cognitive impairment: A systematic review. BMC Neurol. 2019;19(1):1-10.

9. Roche F. Obstructive sleep apnea, daytime hypersomnolence and cognitive decline: a scary waterfall? [Internet]. Vol. 23, Sleep Medicine. Elsevier B.V.; 2016 [cited 2016 Aug 15]. p. 978. Available from: http://dx.doi.org/10.1016/j.sleep.2016.03.020

10. El Hangouche AJ, Jniene A, Aboudrar S, Errguig L, Rkain H, Cherti M, et al. Relationship between poor quality sleep, excessive daytime sleepiness and low academic performance in medical students. Adv Med Educ Pract. 2018; Volume 9:631-8.

11. Zhou J, Camacho M, Tang X, Kushida CA. A review of neurocognitive function and obstructive sleep apnea with or without daytime sleepiness [Internet]. Vol. 23, Sleep Medicine. Elsevier B.V.; 2016 [cited 2016 Mar 2]. p. 99108. Available from: http://dx.doi.org/10.1016/j.sleep.2016.02.008

12. Sforza E, Roche F. Chronic intermittent hypoxia and obstructive sleep apnea: an experimental and clinical approach. Hypoxia. 2016;99.

13. Dewan NA, Nieto FJ, Somers VK. Intermittent hypoxemia and OSA: Implications for comorbidities. Chest. 2015;147(1):266-74. 
14. Azad MC, Fraser K, Rumana N, Abdullah AF, Shahana N, Hanly PJ, et al. Sleep disturbances among medical students: A global perspective. J Clin Sleep Med. 2015;11(1):69-74.

15. Fenny, Supriatmo. Kualitas Tidur Dan Prestasi Belajar Pada Mahasiswa Fakultas Kedokteran. J Kedokt. 2016;5(3):140-7.

16. Appleton S, Gill T, Taylor A, McEvoy D, Shi Z, Hill C, et al. Influence of gender on associations of obstructive sleep Apnea symptoms with chronic conditions and quality of life. Int $\mathbf{J}$ Environ Res Public Health. 2018;15(5).

17. Simonds A, Wilfried de B. ERS Handbook of Respiratory Sleep Medicine [Internet]. 2012 [cited 2012 Sep 1]. p. 21-4. Available from: http://books.google.ro/books/about/ERS_Hand book_of_Respiratory_Sleep_Medici.html?id=x Nf8IGK81qkC\&pgis=1

18. Franklin KA, Lindberg E. Obstructive sleep apnea is a common disorder in the population-A review on the epidemiology of sleep apnea. $\mathbf{J}$ Thorac Dis. 2015;7(8):1311-22.

19. Jäncke L. Sex/gender differences in cognition, neurophysiology, and neuroanatomy [version 1; referees: 3 approved]. F1000Research. 2018;7(0):1-10.

20. Taleb A, Awamleh A. Gender Differences in Cognitive Abilites. Curr Res Psychol. 2012;3(1):33-9.

21. Bilyukov RG, Nikolov MS, Pencheva VP, Petrova DS, Georgiev OB, Mondeshki TL, et al. Cognitive impairment and affective disorders in patients with obstructive sleep apnea syndrome. Front Psychiatry. 2018;9(AUG):1-11.

22. Dewi.S. Hubungan Antara Fungsi Kognitif dengan Riwayat Obstructive Sleep Apnea (OSAS) pada Pasien Pasca Stroke Iskemik di RSUP Dr Kariadi. 2016;

23. Otero L, Del Maria, Alain R HP. Cognitive Impairment and Obstructive Sleep Apnea [Internet]. Sleep neurology and Obstructive Sleep Apnea. InTech; 2019 [cited 2019 Jan 11]. Available from: https://www.intechopen.com/onlinefirst/cognitive-impairment-and-obstructivesleep-apnea 